\title{
Rapid health systems change: online medical consultations to fight COVID-19
}

\author{
Haiyin Wang ${ }^{1}$, Peipei Song ${ }^{1,2}$, Yuanyuan Gu$^{3}$, Elizabeth Schroeder ${ }^{3,4}$, Chunlin Jin ${ }^{1}$ \\ ${ }^{1}$ Shanghai Health Development Research Center, Shanghai, China; ${ }^{2}$ Institute for Global Health Policy Research, Bureau of International Health \\ Cooperation, National Center for Global Health and Medicine, Tokyo, Japan; ${ }^{3}$ Centre for the Health Economy, ${ }^{4}$ Department of Health Systems and \\ Populations, Macquarie University, Sydney, NSW, Australia \\ Correspondence to: Peipei Song. Shanghai Health Development Research Center, No. 181 Xinbei Road, Shanghai, China; Institute for Global Health \\ Policy Research, Bureau of International Health Cooperation, National Center for Global Health and Medicine, 1-21-1 Toyama Shinjuku, Tokyo \\ 162-8655, Japan. Email: ppsong-tky@umin.ac.jp. \\ Provenance and Peer Review: This article was a free submission to the journal. The article did not undergo external peer review.
}

Submitted Mar 17, 2020. Accepted for publication May 13, 2020.

doi: $10.21037 /$ atm-20-2618

View this article at: http://dx.doi.org/10.21037/atm-20-2618

Coronavirus disease 2019 (COVID-19) was firstly reported in Wuhan, Hubei, China in December 2019. Its mode of transmission was exacerbated by the "Spring Festival travel rush" which enabled it to become epidemic in China. Now, it has become an unprecedented challenge globally with the spreading COVID-19 pandemic.

The rapid growth in infections and deaths caused anxiety, panic, and rumormongering in the early days in China (1), which led to a large number of people seeking medical care in hospitals, overwhelming the healthcare system and potentially placing many people at risk of cross-infection. Limited time outdoors with home-based quarantine became a measure of health care management, though it created the unintended impediment for access to necessary care services.

In response, internet-based medical enterprises in China quickly launched online platforms and renowned health professionals began providing free consultations and livestreaming to provide health information. Many online apps emerged, including Ali Health, WeDoctor, Ping An Good Doctor, and haodf.com. Online medical consultations rapidly became the preferred option of choice. As of 29 February, 160,000 online consultations were provided by 28 internet hospitals in Shenzhen (2). And Tianjin's WeDoctor Internet Hospital, an online medical consultation service only established in late January 2020, received 20 million visits in its first month (3).

These online hospitals have provided a broad range of services: epidemic updates, symptom diagnosis, psychological counselling, guidance for self-quarantine, follow-up care for chronic disease and health management. For example, haodf.com has provided free daily online care services for patients quarantined at home; where patient data is collected through online self-completed forms and is monitored by a medical team who offer health guidance until the end of quarantine.

The online medical consultations have been shown to be highly effective in avoiding cross-infection, mitigating anxiety, relieving health system pressures, and promoting hierarchical care. It also seems that online medical experience has been proven convenient $(4,5)$; as of 1 March 2020, following the opening of online health services, patient visits to fever clinics in the Zhejiang province declined by $50 \%$ (6).

The value provided by online medical consulting services during the COVID-19 epidemic has also been recognized by the Chinese government. Previously the Government monitored growth in the online medical care market with caution. In principle, online doctors were only allowed to attend to repeat prescriptions and follow-up consultations. A draft government policy from 2017 even recommended internet hospitals be shut down (7). COVID-19 seems to have radically changed this policy stance; and on the $4^{\text {th }}$ and $7^{\text {th }}$ of February the Chinese National Health Commission issued two policy documents, asking every province to make full use of the advantages of internet-based consulting 


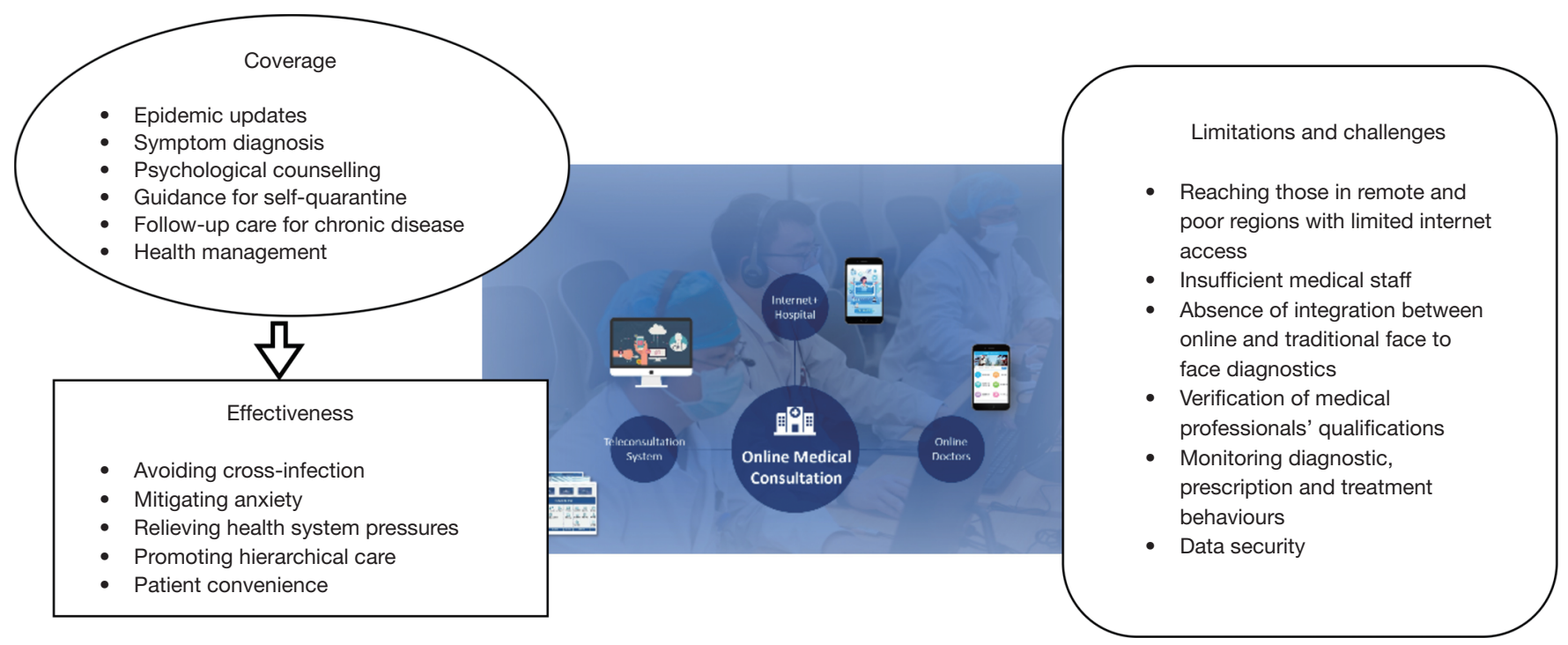

Figure 1 The coverage, effectiveness and limitations of online medical consultations.

services for diagnosis and treatment. On the $2^{\text {nd }}$ March, and for the first time, the National Healthcare Security Administration issued another policy, allowing eligible internet hospitals and medical institutes (already permitted to run online services) to have their follow-up consultations for chronic diseases financially reimbursed by the national health-insurance scheme. Here electronic prescriptions, with diagnosis and drug expenses are recorded and are paid through the public health insurance (the insured part) and personal banking (the co-payment). Drugs (or pharmaceuticals) can be obtained in various ways, from a patient's community pharmacy store or home delivery.

While the value of online medical consultations in scaffolding public health care responses to the epidemic is uncontested, constraints, risks and inequities do exist, such as for those residing in remote and poor regions with limited internet access, insufficient medical staff, and the absence of integration between online and traditional face to face diagnostics. Moreover, verification of medical professionals' qualifications, and their diagnostic, prescription and treatment behaviours, and data security are not likely to be stringently regulated (Figure 1). Only when both safety and quality can be ensured, and treatment fidelity be evaluated compared to face to face consultations, should online medical consulting gain the appropriate trust and recognition of the public and scale-up to become a regular choice among healthcare options.

More broadly, as of $15^{\text {th }}$ March, there were 153,517 cases of COVID-19 across 144 countries and territories (8).
Tackling COVID-19 has now become the most pressing global issue. In some countries, medical consultation via telephone has become the default and preferred pathway. For example, in the United Kingdom the public are recommended to first call NHS111 for a consultation. The UK has an established and monitored system of telecommunication, effectively funded within the NHS. The Australian Government announced reimbursement for primary care services delivered via 'telehealth' to 30 September 2020 in the first instance, as an interim COVID-19 measure to supplement face to face consultations. For other countries, whilst telephone consultations can be useful supplementary tools, their provision and integration are less mature and might be a weaker means for diagnosis, treatment and care management.

Countries differ to the extent that they engage with the increasing proliferation of online and digital technologies, and to how these are integrated into routine medical practice (9). Whilst we applaud China for utilizing online medical consulting services to contain COVID-19, and to creatively manage healthcare constraints, we propose that the quality and safety of the online services be closely monitored to protect population health, and to further develop them into important weapons to tackle infectious disease outbreaks in the future.

\section{Acknowledgments}

Funding: This work was supported by the Shanghai Health 
Insurance Association, Shanghai, China.

\section{Footnote}

Conflicts of Interest: All authors have completed the ICMJE uniform disclosure form (available at http://dx.doi. org/10.21037/atm-20-2618). The authors have no conflicts of interest to declare.

Ethical Statement: The authors are accountable for all aspects of the work in ensuring that questions related to the accuracy or integrity of any part of the work are appropriately investigated and resolved.

Open Access Statement: This is an Open Access article distributed in accordance with the Creative Commons Attribution-NonCommercial-NoDerivs 4.0 International License (CC BY-NC-ND 4.0), which permits the noncommercial replication and distribution of the article with the strict proviso that no changes or edits are made and the original work is properly cited (including links to both the formal publication through the relevant DOI and the license). See: https://creativecommons.org/licenses/by-nc-nd/4.0/.

\section{References}

1. Bao Y, Sun Y, Meng S, et al. 2019-nCoV epidemic: address mental health care to empower society. Lancet 2020;395:e37-8.

2. Shenzhen foreign affairs office service center, Daily briefing on fighting against COVID-19. Cited 2020 Mar 9.

Cite this article as: Wang H, Song P, Gu Y, Schroeder E, Jin C. Rapid health systems change: online medical consultations to fight COVID-19. Ann Transl Med 2020;8(11):726. doi: $10.21037 /$ atm-20-2618
Available online: http://www.szfaosc.com/newscentre/info. aspx? itemid=316

3. China Daily. Online doctors offer free services. Cited 2020 Mar 2. Available online: https://www.chinadaily.com.cn/ a/202003/02/WS5e5c9c85a31012821727b988.html

4. Wu D, Hesketh T, Shu H, et al. Description of an online hospital platform, China. Bull World Health Organ 2019;97:578-9.

5. China Daily. Internet healthcare serving homebound patients. Cited 2020 Mar 13. Available online: https://www.chinadaily.com.cn/a/202003/13/ WS5e6ae6f3a31012821727ed09.html

6. National Health Commission of the People's Republic of China. Online health services play role in COVID-19 fight. Cited 2020 Mar 1. Available online: http://en.nhc. gov.cn/2020-03/01/c_77147.htm

7. The Economist. Millions of Chinese, cooped up and anxious, turn to online doctors. Cited $2020 \mathrm{Mar}$ 5. Available online: https://www.economist.com/ business/2020/03/05/millions-of-chinese-cooped-up-andanxious-turn-to-online-doctors

8. WHO. Coronavirus disease (COVID-2019) situation reports-55. Cited 2020 Mar 16. Available online: https://www.who.int/docs/default-source/coronaviruse/ situation-reports/20200315-sitrep-55-covid-19. pdf?sfvrsn=33daa5cb_6

9. Marshall M, Shah R, Stokes-Lampard H. Online consulting in general practice: making the move from disruptive innovation to mainstream service. BMJ 2018;360:k1195. 